\title{
ESTABILIDADE ATMOSFÉRICA E COMPORTAMENTO DE ZONAS CLIMÁTICAS LOCAIS EM SÃO JOSÉ DO RIO PRETO - SP
}

MASIERO, Érico - ericomasiero@yahoo.com.br

Pontifícia Universidade Católica de Campinas

SOUZA, Léa Cristina Lucas de - leacrist@ufscar.br

Escola de Engenharia de São Carlos

RESUMO: Este estudo investiga a influência do grau de estabilidade atmosférica para a detecção de microclimas urbanos. O enfoque é verificar a variação de temperatura entre a área rural e urbana em condição de atmosfera estável e instável, segundo a classificação de Pasquil, Guifford e Turner, para fins de análise aplicada ao planejamento microclimático do ambiente térmico urbano. Tanto o ambiente construído quanto as condições do tempo meteorológico são responsáveis pelas variações de temperatura e umidade no ambiente urbano. Desta forma, se torna necessário aprimorar os métodos de recortes de tempo e espaço para o desenvolvimento de pesquisas sobre clima urbano. Cinco sensores termo higrométricos foram distribuídos em diferentes Zonas Climáticas Locais - LCZs - na cidade de São José do Rio Preto, SP, Brasil, sendo, uma área rural, uma próxima a um corpo d'água, uma no centro urbano e outras duas em um bairro residencial periférico. As variações de temperatura foram monitoradas de acordo com duas condições atmosféricas distintas, uma instável e outra estável subsequentemente. Os resultados indicaram que, sob condições de instabilidade atmosférica, a diferença entre o comportamento de temperatura nos cinco pontos foi menor que $2^{\circ} \mathrm{C}$ e, sob condições atmosféricas estáveis a diferença tende a aumentar. Destaca-se que, as maiores diferenças detectadas entre os valores de temperatura ocorreram entre a área ao redor do corpo d'água e o bairro periférico. Tais diferenças evidenciam a expressiva influência dos elementos urbanos sobre o microclima, principalmente durante o período mais estável da atmosfera. Conclui-se que, para o período mais instável da atmosfera, a absorção de energia pelo ambiente construído e a pluma de umidade exercida pelo corpo d'água sobre a cidade ficam menos perceptíveis e a variação de temperatura entre os pontos avaliados tende a se aproximar. Assim, a cuidadosa seleção, tanto do recorte de tempo quanto do recorte de espaço em pesquisas sobre clima urbano, se torna fundamental para a avaliação de microclimas urbanos.

Palavras chave: microclima, estabilidade atmosférica, ambiente térmico urbano. ATMOSPHERIC STABILITY AND BEHAVIOR OF LOCAL CLIMATE ZONES IN SÃO JOSÉ DO RIO PRETO - SP

ABSTRACT: This study investigates the degree influence of the atmospheric stability on the urban microclimate detection. The main focus is to check the temperature variation between rural and urban areas in conditions of stable and unstable atmosphere, according to the Pasquil Guifford and Turner classification, for urban microclimate planning and thermal environment analysis. Thus, it is necessary to improve the clippings methods of time and space for the research development on urban climate. Five thermo-hygrometer sensors were distribute 
in different Local Climate Zones - LCZ - in the city of São José do Rio Preto, SP, Brazil, being one in a rural area, another near a water body, one in the city center and other two in a peripheral residential neighborhood. The temperature variations were monitored according to two different atmospheric conditions, an unstable and another one stable thereafter. The results indicated that, under unstable atmospheric conditions, the difference between the behavior of the five points of temperature was less than $2^{\circ} \mathrm{C}$, under stable atmospheric conditions, the difference tends to increase. It is noteworthy that the greatest detected differences between the temperature values occurred between the area around the water body and the peripheral area. Such differences highlight the significant influence of urban elements on microclimate, especially during the most stable period of the atmosphere. It is concluded that for the most unstable period of the atmosphere, the energy absorption by the built environment and the carried moisture plume by the water body over the city are less noticeable, and the temperature variation between the points tends to be closer. Thus, careful selection as much as the clipping time as the cutout space on urban climate research becomes essential for the evaluation of urban microclimates.

\section{INTRODUÇÃO}

Desde os primórdios dos estudos de climatologia urbana de Luke Howard durante a revolução industrial na Inglaterra, passando pelos estudos de Chandler (1965), Landsberg (1981) e Oke (1987) pairam ainda questões que merecem atenção dos pesquisadores em relação aos recortes ideais de tempo e espaço que tenham a capacidade de representar os principais fenômenos associados à alteração da atmosfera sobre as cidades. Em princípio, é necessário que se compreendam as condicionantes climáticas genericamente e a gênese de um assentamento humano, para se estabelecer os recortes têmporoespaciais específicos, que auxiliem o planejamento de campanhas de coletas de dados de campo em áreas urbanas.

Tal dificuldade decorre por duas principais razões: uma, em função da limitação dos estudos em clima urbano em levantar dados de campo por longos períodos, devido à disponibilidade de equipamentos de pesquisa e estações meteorológicas; e, outra, em função da rápida transformação espacial das cidades brasileiras, a qual pode influenciar os padrões de ocupação urbana durante uma campanha de coleta de dados muito extensa.

A abordagem metodológica utilizada por Monteiro \& Mendonça (2011), para cidades de médio porte consiste na definição da área de estudo e na abordagem do subsistema como, por exemplo, termodinâmico, físico-químico ou hidrometeorológico. Nesta etapa se detectam os movimentos típicos das massas de ar em macroescala, se caracterizam os principais fenômenos climáticos regionais, que possivelmente possam interferir ou contribuir com a qualidade das coletas de dados e, simultaneamente, ocorre à escolha dos fenômenos urbanos a serem estudados. 
A compreensão da circulação das massas de ar de uma determinada região geográfica é o princípio fundamental da climatologia dinâmica. Esta objetiva avaliar a tendência de movimento, da trajetória, da frequência e das características gerais das frentes ou ciclones atuantes em uma determinada região. Tais conceitos são componentes decisivos para a compreensão dos fenômenos que regem os conceitos da climatologia urbana. O clima urbano é entendido aqui como um sistema que abrange o clima de um espaço terrestre e sua urbanização, o qual está subordinado aos fenômenos da dinâmica

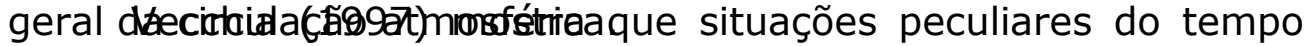
atmosférico podem ser analisadas por meio de episódios climáticos representativos de determinado período, e que a magnitude, a intensidade, a extensão e a duração da atuação de um sistema atmosférico se alteram de acordo com a estação do ano. 0 comportamento térmico dos espaços construídos e abertos pode ser avaliado por intermédio da análise de uma sequência característica da massa de ar atuante no local e, entende-se que as subsequentes influências de elementos urbanos possam alterar, em escala microclimática, o comportamento físico dos ambientes.

Segundo Gartland (2010), Oke (1987), Weber \& Kuttler (2007) e Masiero \& Souza (2013) é durante os períodos mais quentes, secos e estáveis que os efeitos do clima urbano podem ser sentidos. Krüger \& Emmanuel (2013) relatam também que o efeito dos parâmetros urbanos, como a morfologia, a altura dos edifícios, a cobertura vegetal e as propriedades térmicas das superfícies se tornam mais evidentes sob condições estáveis da atmosfera.

Para se estabelecer os períodos mais representativos do clima urbano é importante interpretar os dados meteorológicos de modo a extrair os períodos mais estáveis da atmosfera. Mohan \& Siddiqui (1998) esclarecem que o termo estabilidade atmosférica qualifica o comportamento atmosférico que governa as acelerações do movimento vertical do ar. Quando a aceleração dos fluxos verticais de ar é positiva, a atmosfera é classificada como instável ou turbulenta; quando o valor da aceleração é zero, seu estado é neutro; e, quando há desaceleração, a atmosfera é estável ou com turbulência reprimida. Os autores também relatam que o comportamento da estabilidade atmosférica recebeu até o final da década de sessenta seis principais classificações; A altamente instável ou convectiva, B - moderadamente instável, C - pouco instável, D - neutra, E - moderadamente estáveis e F extremamente estável. Turner (1970) incluiu uma sétima classificação para representar vento fraco e considerar o comportamento atmosférico em noites estáveis, batizado de $\mathrm{G}$. Assim, foi estabelecida a classificação atmosférica conhecida como PGT - Pasquill, Guifford e Turner - muito utilizada 
internacionalmente para estudos de dispersão de plumas de poluentes atmosféricos.

Determina-se a estabilidade atmosférica comparando a diferença de temperatura de uma parcela de ar ascendente ou descendente com o perfil de comportamento de temperatura do ar ambiente. O grau de instabilidade influencia a intensidade da convecção do ar e do resfriamento adiabático, provocando a condensação da umidade e o surgimento de nuvens. Esta classificação recorre a parâmetros climáticos para determinar o grau de estabilidade atmosférica do ar, como a velocidade do vento, a intensidade da radiação solar do período e a cobertura por nuvens no período noturno.

Para se estabelecer os locais mais representativos dentre a complexidade dos ambientes urbanos, Oke (2006) sugere a classificação em Zonas Climáticas Urbanas - Urban Climate Zones - UCZ. O objetivo é identificar o potencial de cada área em alterar o clima local e caracterizar a transição entre as diferentes áreas. As escalas são conferidas pelas dimensões das características morfológicas que compõem uma paisagem urbana. Assim é necessário descrever as propriedades das áreas urbanas que podem afetar a atmosfera em relação à estrutura, a cobertura das superfícies, o tecido e o metabolismo urbano.

Stewart \& Oke (2012) recorrem ao estudo da paisagem para uma nova classificação climática especificamente para estudos em áreas urbanas. Nesse caso, determinam-se unidades com características físicas e culturais que conferem à paisagem, propriedades que podem influenciar a temperatura na camada intraurbana. É considerado que a forma da estrutura afeta o clima local através da modificação dos fluxos de ar, do transporte do calor atmosférico e de saldos de radiação de ondas curtas e longas. Enquanto que a cobertura das superfícies tem a capacidade de alterar o albedo, a disponibilidade potencial de umidade e o aquecimento e arrefecimento do solo. Assim, se torna possível classificar a paisagem dividindo-a em estruturas com propriedades aproximadamente homogêneas e gerar dezessete classes de protótipos semelhantes. Tal critério de classificação da paisagem foi denominado Zonas Climáticas Locais - Local Climate Zones - LCZ. As Zonas Climáticas Locais são definidas como regiões com estrutura, materiais, atividades humanas, cobertura de superfície uniformes que se estendem por centenas de metros horizontalmente. Cada LCZ é caracterizada de acordo com um determinado regime de temperatura sobre superfícies secas, com atmosfera calma, noites claras em áreas com relevo suave.

A partir da classificação proposta por Oke (2006) em Zonas Climáticas Urbanas - UCZ - Stewart \& Oke (2012) aprimoraram os métodos e desenvolveram um sistema de avaliação de sítios urbanos com base em critérios como Fator de Visão do Céu, Altura e Largura dos Cânions Urbanos, Fração da superfície construída, Fração da superfície impermeável do solo, Proporção de área permeável do solo e a Rugosidade dos elementos que compõem a paisagem. 
Este estudo se propõe para tanto, investigar como o grau de estabilidade atmosférica pode influenciar na detecção de microclimas urbanos e talvez gerar falhas de interpretação de dados climáticos em estudos de clima urbano. O enfoque é verificar a variação de temperatura entre cinco áreas classificadas de acordo com a metodologia de Stewart \& Oke (2012), sendo, uma área rural, uma próxima a um corpo d'água, uma no centro urbano, outras duas em um bairro residencial periférico e em duas condições atmosféricas, uma estável e outra instável segundo a classificação de Pasquil, Guifford e Turner, descrita por Mohan \& Siddiqui (1998). Assim, procura-se despertar o interesse para importância no cuidado da avaliação e da interpretação de dados coletados em pesquisas de campo de clima urbano em períodos de tempo e recortes urbanos, que estejam de acordo com técnicas de estudo consagradas internacionalmente.

\section{MATERIAIS E MÉTODOS}

A metodologia adotada se baseia em três etapas, sendo: 1 a Caracterização dos recortes urbanos em Zonas Climáticas Local - LCZ de acordo com a metodologia de Stewart \& Oke (2012). 2 o registro de dados de campo de hora em hora de temperatura, umidade, velocidade do vento e radiação solar nos locais definidos durante o mês de outubro. 3 - o recorte temporal e a detecção do horário mais estável e do mais instável período de coleta de dados de acordo com a metodologia de Pasquil, Guifford e Turner - PGT.

\section{Caracterização física de S. J. Rio Preto e dos recortes urbanos}

São José do Rio Preto está localizada ao Norte do Estado de São Paulo nas coordenadas $20^{\circ} 49^{\prime} 11^{\prime \prime}$ Latitude Sul e $49^{\circ} 22^{\prime} 46^{\prime \prime}$ Longitude Oeste. A área urbana corresponde a $117,43 \mathrm{~km}^{2}$ e é cortada por um rio de pequeno porte, o Rio Preto que, junto com o córrego dos Macacos, formam as duas represas artificiais na área urbana. A cidade está localizada em altitudes próximas aos 500 metros em relação ao nível do mar e os biomas são caracterizados pela presença marcante de cerrados e resquícios de Mata Atlântica, segundo IBGE (2012).

O sítio sobre o qual se implantou a cidade caracteriza-se por um relevo pouco ondulado com espigões amplos e de modesta altitude, em média $500 \mathrm{~m}$. As rodovias Transbrasiliana BR-153 Federal, na direção NE-SW e a Washington Luiz SP - 310 Estadual, 
na direção E - W influenciaram o direcionamento do crescimento da cidade. A maior concentração populacional da cidade de São José do Rio Preto está contida em um " $v$ " formado pelo cruzamento destas duas rodovias. (PMSJRP, 2010a).

São José do Rio Preto se caracteriza por ser um polo regional, com comércio diversificado e economia dinâmica. As avenidas em fundo de vale e tornaram importantes eixos do sistema viário intraurbano, no entanto, parte dos córregos Canela e Borá tiveram suas margens suprimidas e foram canalizados e fechados na década de 50 . Rocha et. al. (2011).

A área de espelho d'água das duas Represas Municipais somam quase $9 \mathrm{~km}^{2}$ e são responsáveis pelo abastecimento de $30 \%$ a $40 \%$ da água potável consumida no município após o tratamento no Palácio das Águas.

Peel et. al. (2007) atualizaram o mapa de classificação climática mundial criado por Köppen-Geiger e classificam São José do Rio Preto como Aw, que corresponde ao clima Tropical de Altitude com invernos secos, verões quentes e chuvosos. A temperatura média no inverno fica próxima aos $18^{\circ} \mathrm{C}$ e $30^{\circ} \mathrm{C}$ no verão. A umidade relativa do ar média anual se situa na casa dos $70 \%$ aproximadamente, podendo chegar até abaixo de $20 \%$ nos meses mais secos.

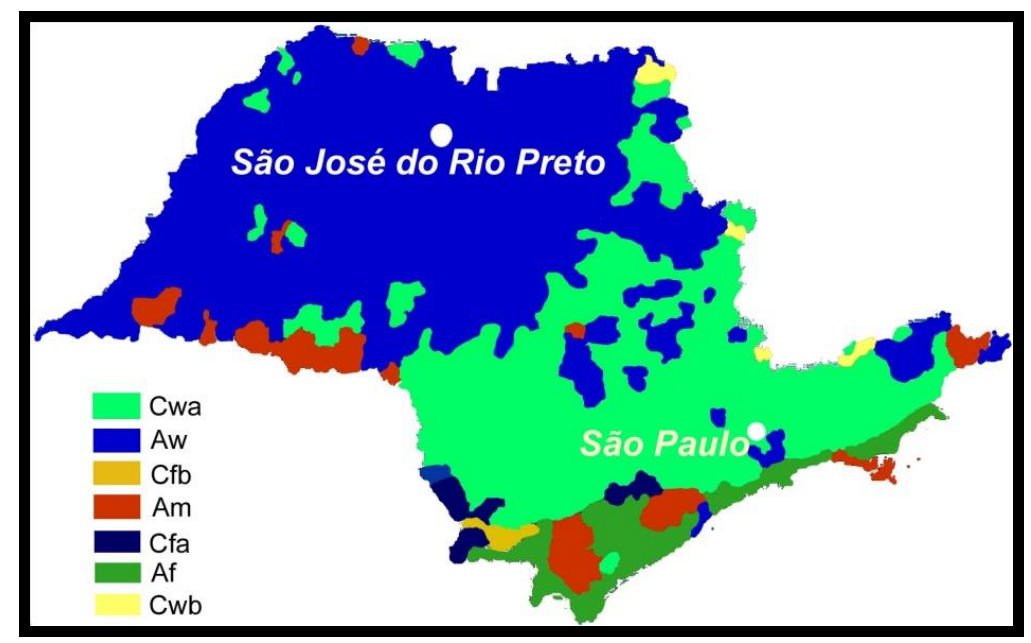

Figura 1 - Adaptado da atualização da classificação climática mundial criada por KöppenGeiger. Fonte: adaptada de Peel et. al. (2007)

O território paulista está situado no limite de duas zonas climáticas - a Intertropical e a Subtropical. Na primeira, o clima é controlado por massas equatoriais e tropicais, enquanto na segunda, por massas tropicais e polares. Esse aspecto determina as características de verão quente e chuvoso e invernos secos. Nimer (1979) relata que fatores de ordem estática e natureza dinâmica se combinam para definir os processos climatológicos da Região Sudeste, a qual está localizada sob a trajetória preferida das frentes polares. Frequentemente, o sistema de 
circulação do anticiclone polar das altas latitudes e o sistema de circulação dos anticiclones do Atlântico Sul das baixas latitudes se combinam em equilíbrio dinâmico, fato que caracteriza a diversificação do clima da região.

De acordo com Monteiro (1973), o território paulista é vulnerável à ação das principais correntes da circulação atmosférica da América do Sul. As massas Tropical Atlântica e Continental, Polar Atlântica e Equatorial Continental, juntamente com os fatores geográficos de posicionamento e relevo, contribuem para definir as características de climas tropicais alternadamente secos e úmidos.

Para que a coleta de dados represente significativamente os fenômenos em uma porção homogênea de uma área urbana é necessário definir a escala de abrangência de estudo. A seleção do recorte urbano deve estar condicionada aos fatores de influências microclimáticas. De tal forma, foi considerada a variação de ocupação de acordo com as características de cada sítio para a instalação dos sensores na campanha de coleta de dados de campo.

Cinco pontos de monitoramento foram selecionados, sendo, uma área rural, uma próxima a um corpo d'água, uma no centro urbano e outras duas em um bairro residencial periférico na região norte da cidade (Figura 2). 


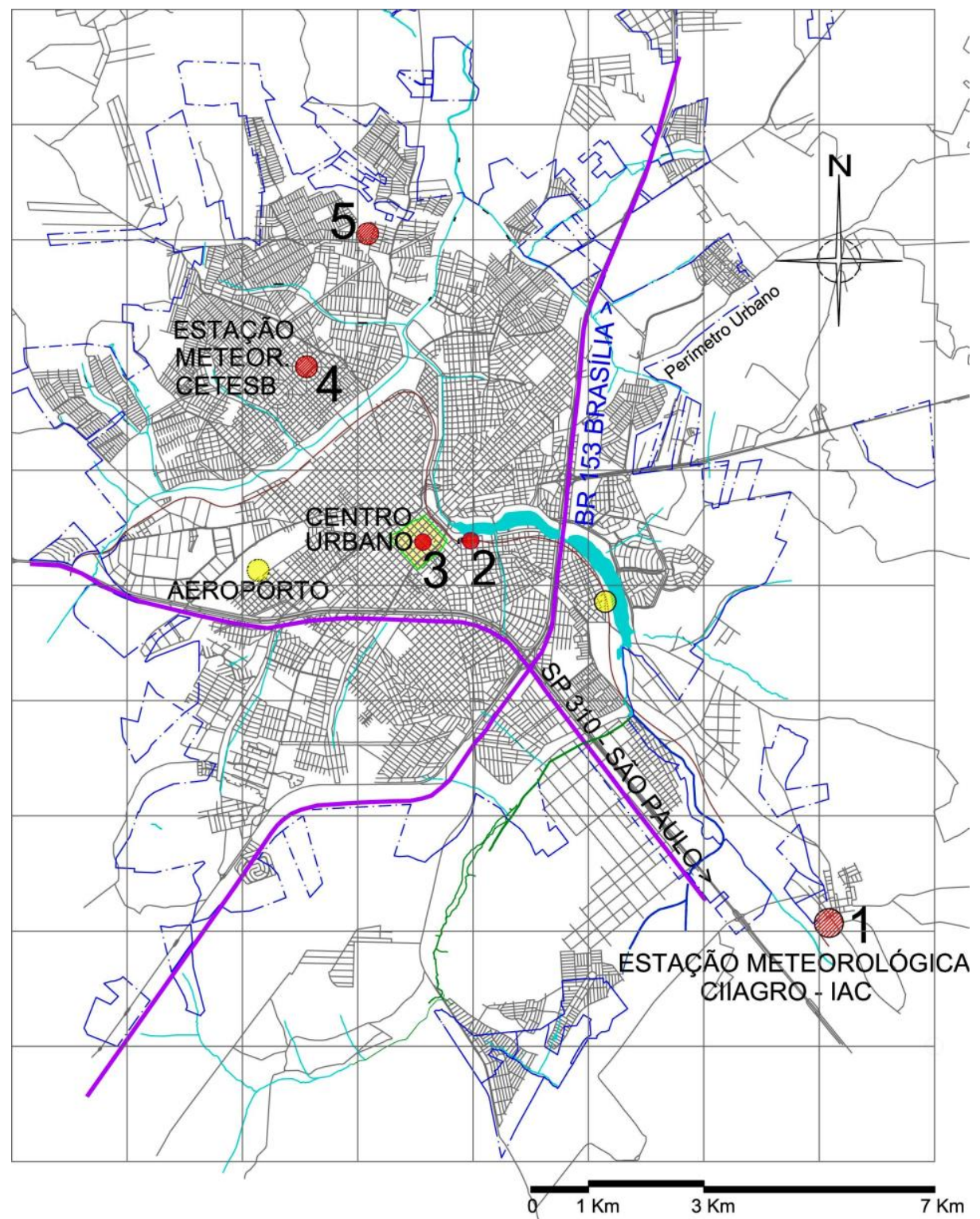

Figura 2 - Localização de pontos de medição Fonte: Adaptada de PMSJRP (2010b)

Para cada recorte urbano selecionado, foram determinados dez aspectos que caracterizaram o ambiente construído, são eles: a área do recorte, a área da superfície construída, as superfícies permeáveis e impermeáveis, a rugosidade do solo e a altura média da rugosidade, a distância do recorte urbano em relação ao corpo d'água, a relação altura e largura (H/W) dos cânions urbanos monitorados, as respectivas classificações proposta por Stewart \& Oke (2012) e a determinação do Fator de Visão do Céu de cada área. Os FVCs foram determinados a partir das imagens geradas por uma lente olho de peixe acoplada à uma câmera fotográfica e posicionada a $1,5 \mathrm{~m}$ do solo, alinhada verticalmente. As imagens foram tratadas posteriormente no programa computacional 
RayMan 1.2 desenvolvido por Matzarakis (2009), conforme as recomendações de Matzarakis et. al. (2010). Os índices que densidade construída e as demais características ambientais dos cinco recortes urbanos estão descritos na Tabela 1.

Tabela 1 - Sistema de caracterização de Zonas Climáticas Locais dos recortes monitorados. Fonte: Adaptada de Stewart e Oke (2012)

\begin{tabular}{|c|c|c|c|c|c|c|c|c|c|c|c|c|}
\hline స్ & 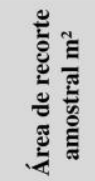 & & $\sum_{2}^{u}$ & 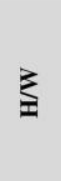 & 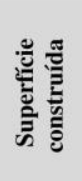 & 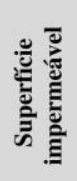 & 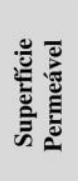 & 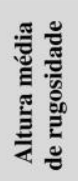 & 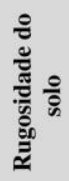 & 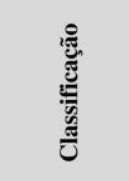 & 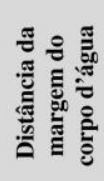 & 冚 \\
\hline 1 & 100.000 & 0,86 & & 0,25 & $5 \%$ & $5 \%$ & $95 \%$ & 3 & 0,5 & $\begin{array}{c}\text { Vegetação } \\
\text { baixa }\end{array}$ & $6.000 \mathrm{~m}$ & \\
\hline 2 & 125.000 & 0,82 & & 0,4 & $15 \%$ & $21 \%$ & $79 \%$ & 5 & 0,3 & $\begin{array}{c}\text { Ocupação } \\
\text { edificações } \\
\text { esparsas }\end{array}$ & $80 \mathrm{~m}$ & \\
\hline 3 & 70.000 & 0,35 & & 4 & $35,8 \%$ & $100 \%$ & $0 \%$ & 30 & 0,1 & $\begin{array}{c}\text { Ocupação } \\
\text { compacta } e \\
\text { gabarito } \\
\text { elevado }\end{array}$ & $1.100 \mathrm{~m}$ & \\
\hline 4 & 100.000 & 0,73 & & 0,4 & $13,5 \%$ & $71 \%$ & $29 \%$ & 5 & 0,2 & $\begin{array}{c}\text { Ocupação } \\
\text { edificações } \\
\text { esparsas }\end{array}$ & $3.500 \mathrm{~m}$ & \\
\hline 5 & 50.000 & 0,57 & & 0,35 & $18 \%$ & $63 \%$ & $37 \%$ & 5 & 0,2 & $\begin{array}{c}\text { Ocupação } \\
\text { compacta e } \\
\text { baixo } \\
\text { gabarito }\end{array}$ & $5.200 \mathrm{~m}$ & \\
\hline
\end{tabular}

O ponto 1, localiza-se em uma área rural no extremo sul de São José do Rio Preto, com atividades predominantemente baseadas na agricultura familiar e em imóveis rurais de veraneio.

0 ponto 2, figuras 19 a 23, localiza-se na margem sul da represa municipal e, apesar de estar localizado próximo ao centro urbano, possui baixa densidade construída. Desta forma, o sensor está sujeito à direta influência da umidade disponibilizada pelo lago e exposto à ação do vento. $O$ ponto 2 foi posicionado no fundo do vale do Rio Preto, o qual apresenta as mais baixas cotas topográficas dentre todas as áreas de estudo.

O Ponto 3 está situado na área central da cidade e suas construções possuem tipologias que variam entre edifícios acima de 15 pavimentos, galpões comerciais e habitações térreas isoladas. Praticamente não há áreas com solo permeável e sem construções que permita a penetração efetiva da umidade disponibilizada pelo corpo d'água. A única exceção no recorte urbano de $100.000 \mathrm{~m}^{2}$ é a Praça Rui Barbosa que, embora seja fartamente arborizada, apresente pisos impermeáveis e com diversos espelhos d'água, há pouquíssima vegetação arbórea e rasteira ao longo das ruas, poucos espaços não construídos, várias 
edificações com $100 \%$ de ocupação do lote e muitas delas sem recuos frontais e laterais. Configuração espacial típica de áreas que concentram atividades comerciais e de prestação de serviços, sofrendo muita influência do calor antropogênico provocado pela excessiva circulação de veículos próxima ao passeio público.

O Ponto 4 está localizado na área periférica da cidade, em um bairro predominantemente residencial da zona norte da cidade, a 3,5 km a noroeste da represa municipal. A área é caracterizada pelas altas taxas de solo impermeabilizado, pouca vegetação e ocupação com habitações isoladas unifamiliares.

O Ponto 5 também está situado na zona norte da cidade, a $6,5 \mathrm{~km}$ a noroeste da represa municipal. Esta área pode ser descrita fisicamente por uma ocupação de residências térreas unifamiliares, com taxa de ocupação de aproximadamente $60 \%$, baixo índice de áreas verdes e solo altamente impermeabilizado. Este ponto, assim como o Ponto 4, está localizado na área mais elevada da cidade, o que a coloca entre as mais áridas da cidade.

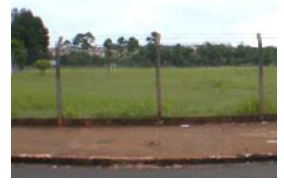

Ponto 1

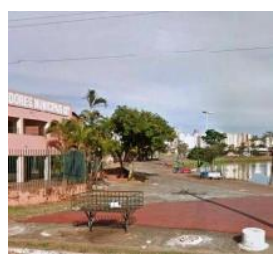

Ponto 2

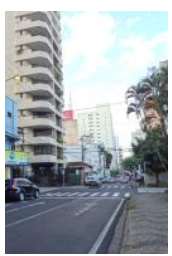

Ponto 3

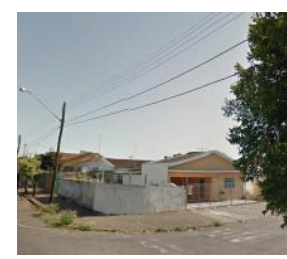

Ponto 4

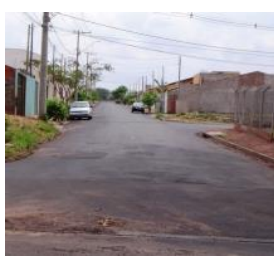

Ponto 5

Figura 4 - Imagens dos locais monitorados

\section{Procedimentos de Medição}

Os dados de temperatura e umidade intraurbanos foram coletados de hora em hora a $3 \mathrm{~m}$ de altura do solo com os sensores HOBO Pro V2 U23-001, colocado dentro de escudos ventilados de PVC, conforme recomendações e especificações do fabricante, nos pontos 2, 3 e 5 . (Figuras 5 e 6 )

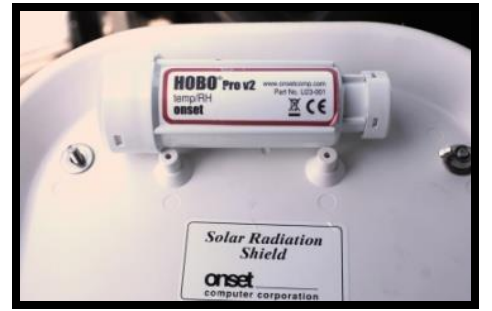

Figura 5 - Sensor HOBO Pro V2 U23-001

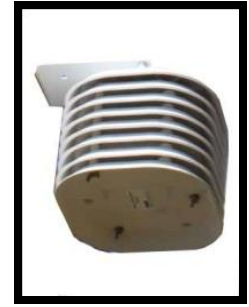

Figura 6 Escudo contra radiação
Faixa de operação: $-40{ }^{\circ} \mathrm{C}$ a $70{ }^{\circ} \mathrm{C}$

Precisão: $0,2^{\circ} \mathrm{C}$ acima de $0^{\circ} \mathrm{C}$ até $50^{\circ} \mathrm{C}$ Resolução: $0,02{ }^{\circ} \mathrm{C}$ a $25^{\circ} \mathrm{C}$

Tempo de resposta:

$40 \mathrm{~min}$ no ar em movimento de $1 \mathrm{~m} / \mathrm{s}$

Especificações Técnicas do Fabricante Fonte: ONSET Brasil (2013)

Para auxiliar a tarefa de caracterização dos fenômenos atmosféricos em macroescala, foram registrados dados de duas estações meteorológicas localizadas nas áreas de estudo e disponibilizados via Ano 10 - Vol. 15 - JUL/DEZ 2014 
web. Foram registrados os dados de temperatura, umidade, velocidade e direção do vento e radiação solar dos pontos 1 e 4 . Respectivamente. As estações são:

(2012)

Instituto Agronômico de Campinas - IAC CIIAGRO

- Companhia Ambiental do Estado de São Paulo CETESB (2012)

A estação meteorológica da CETESB está localizada na área periférica da cidade em um bairro predominantemente residencial a noroeste da Represa Municipal. A Estação Meteorológica do CIIAGRO - IAC está situada em área rural e pode ser utilizada como padrão de referência das análises.

A estação da CETESB é uma estação de monitoramento automático, portanto disponibiliza dados relativos à qualidade do ar urbano, dos parâmetros meteorológicos e de níveis de poluentes presentes no ar. Nela, o equipamento utilizado é um termo-higrômetro, instalado a uma altura de 3,0 m em relação ao solo. A faixa de trabalho para temperatura do ar está entre $-30{ }^{\circ} \mathrm{C}$ e $70{ }^{\circ} \mathrm{C}$, com precisão de medida de $0,1^{\circ} \mathrm{C}$. (CETESB, 2012)

O Instituto de Pesquisa da Agência Paulista de Tecnologia dos Agronegócios, da Secretaria de Agricultura e Abastecimento do Estado de São Paulo, IAC, tem sede no município de Campinas. Entre as atividades desenvolvidas está o serviço prestado pelo Centro Integrado de Informações Agrometeorológicas (CIIAGRO, 2012). Este, operacionaliza e disponibiliza informações e aconselhamento às atividades agrícolas, com base nos parâmetros agrometeorológicos e na previsão do tempo, a partir de uma rede de coleta de dados em todo o estado.

O padrão da altura da medição nas estações do IAC é de aproximadamente $3 \mathrm{~m}$ acima da superfície vegetada. O sensor de temperatura e umidade utilizado é um HMP45, da Campbell, cuja faixa de medição de temperatura vai de $-39,2^{\circ} \mathrm{C}$ a $60{ }^{\circ} \mathrm{C}$, com precisão de $\pm 0,5^{\circ} \mathrm{C}$.

\section{Recorte temporal}

A detecção do horário mais estável e do mais instável do período de coleta de dados ocorreu de acordo com a metodologia de Pasquil, Guifford e Turner - PGT. Esta classificação recorre a parâmetros climáticos para determinar o grau de estabilidade atmosférica do ar, como a velocidade do vento, a intensidade da radiação solar do período e a cobertura por nuvens no período noturno. Desta forma, a combinação entre estes parâmetros definem o grau de estabilidade atmosférica de acordo com a Tabela 2. 
Tabela 2 - Classificação Atmosférica

Fonte: Adaptada de Mohan \& Siddiqui (1998)

\begin{tabular}{|cccccccc|}
\hline \multirow{2}{*}{$\begin{array}{c}\text { Velocidade } \\
\text { do vento } \\
(\mathrm{m} / \mathrm{s})\end{array}$} & \multicolumn{3}{c}{ Insolação Diurna $\left(\mathrm{W} / \mathrm{m}^{2}\right)$} & \multicolumn{4}{c|}{ Cobertura Nuvens Período Noturno } \\
\cline { 2 - 8 } (octas) \\
\hline$\leq 2$ & Alta & Moderada & Baixa & Nublada & Baixa & Moderada & Alta \\
\hline $2-3$ & A & A - B & B & C & G - F & F & D \\
\hline $3-5$ & B & B - C & C & C & E & D & D \\
\hline $5-6$ & C & C - D & D & D & D & D & D \\
\hline$>6$ & C & D & D & D & D & D & D \\
\hline
\end{tabular}

Os valores referentes à Insolação diurna e a Cobertura de Nuvens no período noturno se dão de acordo com as indicações na Tabela 3. No entanto, as estações meteorológicas disponibilizam apenas dados sobre a radiação solar e não da cobertura de nuvens. Tais análises foram feitas a partir das imagens do satélite GOES, disponibilizadas pelo CPTEC-INPE (2012) e as unidades de classificação não foram consideradas.

Tabela 3 - Tabela de insolação e cobertura de nuvens

Fonte: Adaptada de Mohan \& Siddiqui (1998)
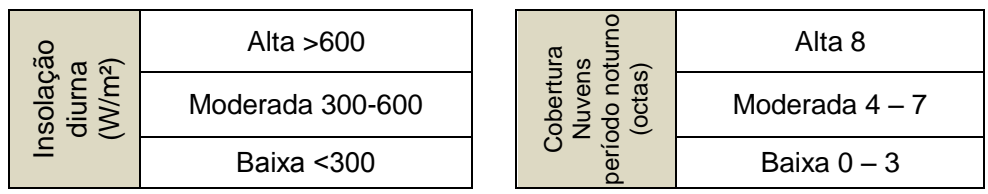

\section{RESULTADOS E DISCUSSÃO}

A partir dos valores registrados de hora em hora durante o mês de Outubro 2012, foi detectado que o período mais estável da atmosfera ocorreu entre 05 e 07 de Outubro 2012. Para aquele período, as temperaturas variaram entre $20^{\circ} \mathrm{C}$ e $35^{\circ} \mathrm{C}$ e os valores de radiação solar atingiram aproximadamente $1000 \mathrm{~W} / \mathrm{m}^{2}$, os quais foram os mais elevados do mês de Outubro (Figura 7). 


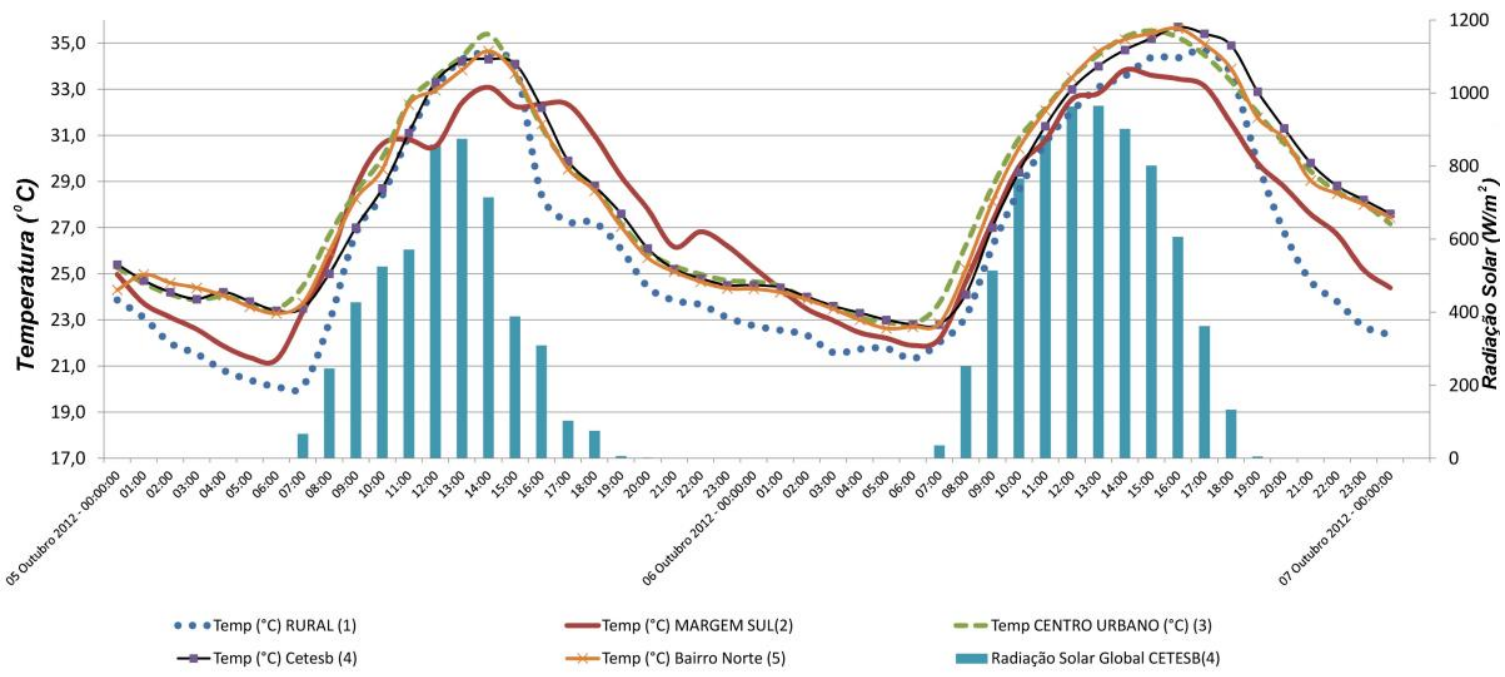

Figura 7 - Variação da temperatura do ar entre 5 pontos urbanos sob condições estáveis de atmosfera

O horário em que foi registrado o maior grau de estabilidade, considerando parâmetros como temperatura, radiação solar, velocidade do vento e cobertura de nuvens foi às $14 \mathrm{~h}$ do dia 05 de Outubro 2012. Tais condições atmosféricas geram uma Classificação PGT - E, a qual coincide com o momento em que ocorrem as maiores diferenças de temperatura entre os cinco pontos de monitoramento microclimático, chegando a registrar diferenças de aproximadamente $3^{\circ} \mathrm{C}$ (Tabela 4).

Tabela 4 - Classificação PGT para atmosfera do dia 5 de Outubro 2012

\begin{tabular}{ll}
\hline & $14 \mathrm{~h}$ do dia 5 de Outubro \\
Horário de Atmosfera diurna mais estável & Radiação solar $859 \mathrm{~W} / \mathrm{m}^{2}$ \\
Classificação PGT - E & Vento Rural $1,8 \mathrm{~m} / \mathrm{s}$ \\
& Céu Claro diurno \\
\hline
\end{tabular}

Durante o período noturno, foi verificado que o maior grau de estabilidade da atmosfera ocorreu as 3h do dia 06 de Outubro 2012. Nesse período foi registrada a menor velocidade do vento de $0,3 \mathrm{~m} / \mathrm{s}$ e a mínima cobertura por nuvens, de acordo com as imagens do satélite GOES (INPE-CPTEC, 2012). Desta maneira, a classificação PGT atribuída a este período foi $\mathrm{G}-\mathrm{F}$, conforme a tabela 5 .

Tabela 5 - Classificação PGT para atmosfera do dia 6 de Outubro 2012

\begin{tabular}{lll}
\hline Horário de Atmosfera noturna mais & 3h do dia 06 de Outubro \\
estável & Radiação solar $0 \mathrm{~W} / \mathrm{m}^{2}$ \\
Classificação PGT - G - F & Vento Rural 0,3 $\mathrm{m} / \mathrm{s}$ \\
\hline
\end{tabular}


Foi verificado que durante o dia 12 de Outubro 2012 a atmosfera apresentou um estado instável e, ao longo do dia 13, a atmosfera se estabilizou. Desta forma, foi possível verificar as influências da estabilidade atmosférica no registro de microclimas urbanos entre os cinco pontos de monitoramento urbano.

Foi constatado que, com a entrada de uma massa úmida de ar atmosférico no início da manhã do dia 12 , as temperaturas dos cinco pontos foram reduzidas e, devido a maior cobertura de nuvens, os valores de radiação solar foram também reduzidos. A radiação solar atingiu valores abaixo de $300 \mathrm{~W} / \mathrm{m}^{2}$ durante a tarde e os ventos atingiram $5 \mathrm{~m} / \mathrm{s}$ provenientes da direção sul. Portanto a Classificação PGT atribuída para o horário das $17 \mathrm{~h}$ foi moderada $(\mathrm{B}-\mathrm{C})$.

Assim, o ganho de calor das superfícies urbanas diminuiu, e, consequentemente a diferença de temperatura entre os cinco pontos de monitoramento chegou a registrar diferenças inferiores a $2^{\circ} \mathrm{C}$. No entanto, conforme a atmosfera se estabilizou gradativamente ao longo do dia 13, as diferenças de temperatura tornaram a registrar valores superiores a $2^{\circ} \mathrm{C}$ (Figura 8 ).

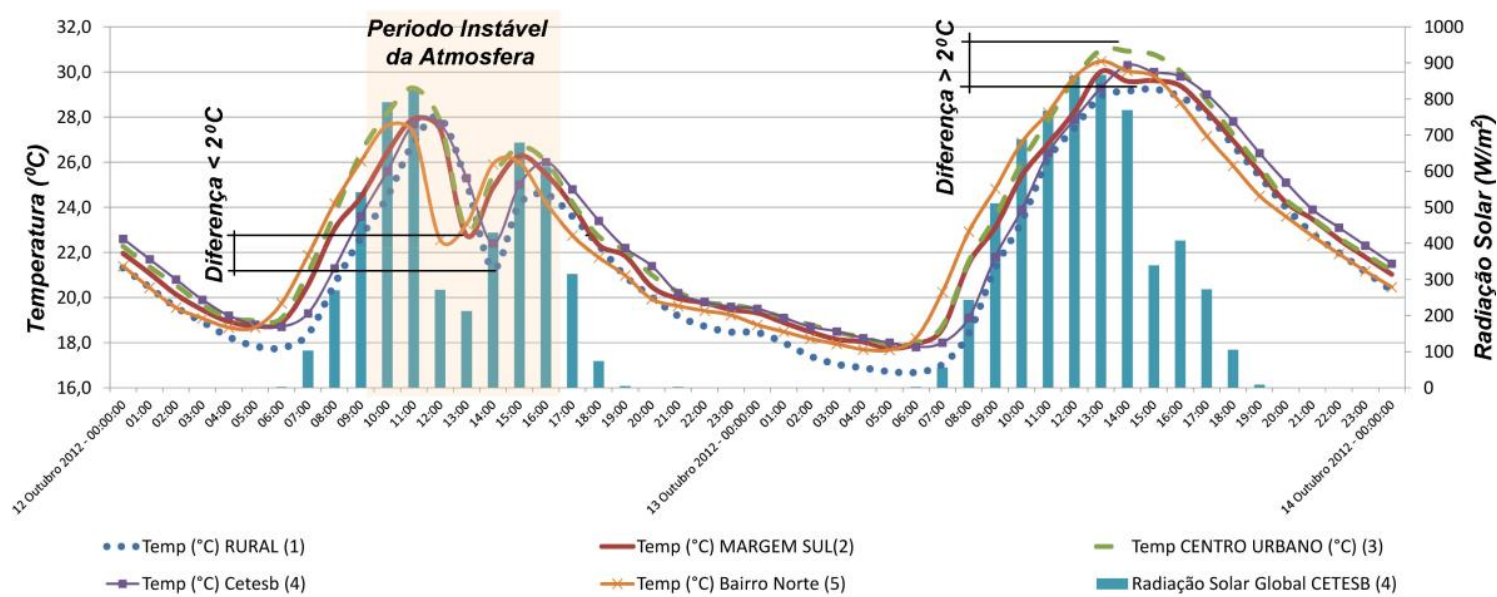

Figura 8 - Variação da temperatura do ar entre 5 pontos urbanos sob condições instáveis e estáveis de atmosfera

Tabela 6 - Classificação PGT para atmosfera do dia 12 de Outubro 2012

\begin{tabular}{ll}
\hline & 17 h do dia 12 de Outubro \\
Horário de Atmosfera diurna mais instável & Radiação solar $315 \mathrm{~W} / \mathrm{m}^{2}$ \\
Classificação PGT - B - C & Vento Rural 5,0 m/s \\
& Céu parcialmente nublado
\end{tabular}




\begin{tabular}{ll}
\hline \multirow{2}{*}{$\begin{array}{l}\text { Horário de Atmosfera noturna mais instável } \\
\text { Classificação PGT - C }\end{array}$} & Radiação solar $0 \mathrm{~W} / \mathrm{m}^{2}$ \\
& Vento Rural $2,1 \mathrm{~m} / \mathrm{s}$ \\
& Céu parcialmente nublado
\end{tabular}

Diversos estudos são desenvolvidos com base em períodos relativamente curtos de levantamento de dados microclimáticos urbanos, portanto, é necessário aprimorar os métodos de recortes têmporoespaciais que resultem em análises consistentes a respeitos das influências do espaço construído nos padrões atmosféricos locais. Os estudos da climatologia dinâmica e dos conceitos de estabilidade atmosférica, assim como as metodologias de recortes urbanos, são cruciais para se caracterizar os efeitos do clima urbano em uma determinada cidade e para a análise dos efeitos microclimáticos.

Destaca-se que as maiores diferenças detectadas entre os valores de temperatura ocorreram entre a margem sul do corpo d'água, o bairro periférico e a área central. Tanto a área central urbana como o bairro situado na região ao norte da cidade apresentam solos altamente impermeabilizados, pouca vegetação arbórea e rasteira e pouca influência da umidade disponibilizada pelo corpo d'água. Tais diferenças físicas evidenciam o expressivo impacto dos elementos urbanos sobre o microclima, principalmente durante o período mais estável da atmosfera.

Stewart \& Oke (2012) relatam que o sistema de classificação em LCZs está menos propenso a confusões decorrentes de generalizações e propõem, inclusive, que os registros de ilhas de calor, por exemplo, sejam estudados a partir de diferenças entre LCZs e não mais a partir da diferença de temperatura entre o ambiente rural e o urbano. Isso é sugerido, principalmente, pelo fato que as LCZs trazem maior rigor no detalhamento das diversas configurações que podem compor uma cidade, as quais geram diversos parâmetros para se determinar as consequências positivas ou negativas de uma intervenção espacial.

O estudo de Collischonn \& Mattos (2011), na cidade de Pelotas RS, demonstra que as rápidas alterações espaciais das fronteiras entre 0 rural e o urbano podem dificultar a definição dos locais para se estabelecer as campanhas de medição e se detectar a variação dos índices microclimáticos no espaço urbano.

Barbosa \& Vecchia (2011), em estudos desenvolvidos na cidade de Maceió, observaram a necessidade de se caracterizar os diversos ambientes em unidades amostrais para descrever com precisão o comportamento térmico de cada unidade urbana. Dessa forma, 
caracterizam-nas dentro do conceito de dia típico, que esteja relacionado a uma sucessão habitual de tipos de tempo e na identificação de um episódio climático representativo. Afirmam, inclusive que, embora os resultados da investigação experimental se limitem à apenas três dias, a qualidade da amostragem pode ser considerada satisfatória.

De acordo com Kruger \& Emmanuel (2013), a diferença entre temperaturas registradas na área urbana e na área rural para a cidade de Glasgow, no Reino Unido, tende a aumentar de acordo com a classe de estabilidade atmosférica PGT. Assim, em condições de instabilidade atmosférica, os fatores geográficos regionais e o ambiente construído exercem menor impacto na formação de microclimas.

Ugeda Junior \& Amorim (2011), em estudos desenvolvidos na cidade de Jales (que está situada a aproximadamente $150 \mathrm{~km}$ a noroeste de São José do Rio Preto), relatam que os ventos fortes e o excesso de chuva durante a fase experimental fizeram com que as diferenças térmicas entre a área urbana e rural, além das intraurbanas, fossem amenizadas. Entretanto, a diferença entre a temperatura do ambiente rural e urbano em dias com atmosfera estável chega a ser superior a $10^{\circ} \mathrm{C}$ durante $o$ período noturno.

\section{CONCLUSÃO}

Conclui-se que, para o período mais instável da atmosfera, a absorção de energia pelo ambiente construído e a pluma de umidade exercida pelo corpo d'água sobre a cidade ficam menos perceptíveis e a variação de temperatura entre os pontos avaliados tende a se aproximar. Assim, a cuidadosa seleção, tanto do recorte de tempo quanto do recorte de espaço em pesquisas sobre clima urbano, se torna fundamental para a avaliação de microclimas urbanos para período curtos de análise.

Os resultados indicaram que, sob condições de instabilidade atmosférica, a diferença entre o comportamento de temperatura nos cinco pontos foi menor que $2^{\circ} \mathrm{C}$ e, sob condições atmosféricas estáveis a diferença tende a aumentar e evidenciar a influência das características ambientais no microclima urbano. Portanto, somente após o conhecimento das características físicas do ambiente urbano e a respeito da dinâmica climática genérica, é que as questões microclimáticas podem ser compreendidas.

Concluindo, os conceitos de análise de estabilidade atmosférica de acordo com a sistemática PGT, assim como a metodologia de classificação em Zonas Climáticas Locais - LCZs - desenvolvida para áreas urbanas por Stewart \& Oke (2012) são ferramentas que contribuem para estudos mais apurados em relação à climatologia 
urbana. Desta forma, somente a partir do domínio dos conceitos de climatologia dinâmica e das consequências das variações dos diversos tipos de tempo que atuam sobre um determinado recorte espacial é que as propostas de intervenções espaciais urbanas devem ser realizadas.

\section{Referências Bibliográficas}

BARBOSA, R., V., R., VECCHIA, F. A. S.. Análise do comportamento térmico de diferentes arranjos urbanos na cidade de Maceió ( $A L$ ) em escala de abordagem microclimática. Pesquisa em Arquitetura e Construção. v.1, No. 4. ISSN 1980-6809. 2011.

CENTRO INTEGRADO DE INFORMAÇÕES AGRO METEOROLÓGICAS - CIIAGRO: Disponível em http://www.ciiagro.org.br/ema/monitoramento.php

Acessado entre 05 e 08 de Outubro 2012.

CENTRO DE PREVISÃO DE TEMPO E ESTUDOS CLIMÁTICOS - CPTEC INPE Disponível: em: http://satelite.cptec.inpe.br/setores/sudeste.jsp Acessado em 10 Dezembro 2012.

CHANDLER, T. J. The climate of London. Hutchinson \& CO Publishers Ltd. London, 292 p. 1965.

COLLISCHONN, E., MATTOS, G. P. de. Classificação de Ambientes Termicamente Homogêneos para Estudos de Clima na Camada do Dossel Urbano - Metodologia e Aplicação à Cidade de Pelotas/RS. Revista Brasileira de Climatologia ISSN: 2237-8642 (Eletrônica). N. 9 - Jul.-Dez.2011

GARTLAND, L. Ilhas de calor: Como Mitigar Zonas de Calor em Áreas Urbanas. São Paulo. Oficina de Textos, 248p. 2010.

INSTITUTO BRASILEIRO DE GEOGRAFIA E ESTATÍSTICA. IBGE Cidades: Informações Sobre Municípios Brasileiros. Acesso em Julho 2012. Disponível em: http://www.cidades.ibge.gov.br/xtras/home.php

KRÜGER, E.L, ROHINTON, Emmanuel. Accounting for atmospheric stability conditions in urban heat island studies: The case of Glasgow, UK. Landscape and Urban Planning. No. 117 p.112- 121. 2013.

KUTTLER, Wilhelm; WEBER, Stephan; SCHONNEFELD, Judith; HESSELSCHWERDT, Alexandra. Urban/rural atmospheric water vapor pressure differences and urban moisture excess in Krefeld, Germany. International Journal of Climatology, 27: 2005-2015, 2007.

LANDSBERG, H. E.. The Urban Climate. International Geophysics series. Volume 28. Academic Press Inc, London, UK. 1981.

MASIERO, E.; SOUZA, L. C. L. de. Variação de umidade absoluta e temperatura do ar intraurbano nos arredores de um corpo d'água. Ambiente Construído, Porto Alegre. ISSN 1678-8621 Associação Nacional de Tecnologia do Ambiente Construído.v. 13, n. 4, p. 25-39, jul./set. 2013. 
MATZARAKIS, A. Rayman 1.2. Disponível em: http://www.mif.unifreiburg.de/rayman/intro.htm acessado em 15 Janeiro 2014

MATZARAKIS, A., RUTZ, F., MAYER, H.. Modelling radiation fluxes in simple and complex environments - Basics of the RayMan model. International Journal of Biometeorology. March 2010, Volume 54, pp 131-139. 2010

MONTEIRO, C. A. F., MENDONÇA, F. Clima Urbano. Editora Contexto. 2ed. São Paulo, 2011.

MOHAN, M., SIDDIQUI, T. A.. Analysis of various schemes for the estimation of atmospheric stability classification. Atmospheric Environment. No. 32(21), p. 3775-3781. 1998.

OKE, T. R. Boundary Layer Climate. 2nd Edition. London. Routledge, 435p. 1987.

OKE, T., Towards better communication in urban climate. Theoretical and Applied Climatology. no. 84, p.179-190. 2006.

ONSET BRASIL. Manuais HOBO U23. Disponível em http://www.onsetcompbrasil.com.br/onsetcomp/manuais/U23-00x/10694-HMAN-U23.pdf. Acessado em 15 Dezembro 2013.

PEEL, M. C.; FINLAYSON, B. L.; MCMAHON, T. A.. Updated world map of the Köppen-Geiger climate classification. Hydrology and Earth System Sciences. No. 11, p. 1633-1644, 2007. Disponível em: http://www.hydrol-earth-systsci.net/11/1633/2007/hess-11-1633-2007.pdf Acessado em 10 Janeiro 2014.

PREFEITURA MUNICIPAL DE SÃO JOSÉ DO RIO PRETO. Secretaria de Planejamento e Gestão Estratégica Municipal, São José do Rio Preto. Conjuntura Econômica de São José do Rio Preto. São José do Rio Preto: Disponível em $<$ http://www.riopreto.sp.gov.br/PortalGOV/do/subportais Show?c $=5050$ $>$ Acessado em 08 Janeiro 2010a.

Disponível Secretaria de Planejamento e Gestão Estratégica Municipal: <http://www.riopreto.sp.gov.br/PortalGOV/do/subportais Show?c $=5050>$. Acessado em 08 Janeiro 2010b.

ROCHA, L. M. V.; SOUZA, L. C. L.; CASTILHO, F. J. V. Ocupação do solo e ilha de calor noturna em avenidas marginais a um córrego urbano. Ambiente Construído (online). v.11, n.3., 2011.

STEWART, I. D., T. R. OKE,. Local Climate Zones for Urban Temperature Studies. Bulletin of American Meteorological Society.no. 93, 2012. p. 1879-1900. doi: http://dx.doi.org/10.1175/BAMS-D-11-00019.1

TURNER, D. B.. Workbook of atmospheric dispersion estimates. Office of Air Program Pub. No. AP-26, Environmental Protection Agency, USA. 1970. 
UGEDA JUNIOR, J., C., TRINDADE AMORIM, M. C. C. Clima Urbano em Jales: Análise do Térmico e Higrométrico para os Meses de Janeiro e Julho 2010. Revista Brasileira de Climatologia. ISSN 2237-8642. Ano 7, v.8 - Jan-Jun 2011.

VECCHIA, F. A. S.. Clima e ambiente construído: a abordagem dinâmica aplicada ao conforto humano. 316p. Tese (Doutorado) - Faculdade de Filosofia, Letras e Ciências Humanas, Universidade de São Paulo, São Paulo, 1997. 